Eastern Illinois University

The Keep

Faculty Research \& Creative Activity

Biological Sciences

January 2002

\title{
Individual variation in the duration of territory occupation by males of the dragonfly Perithemis tenera (Odonata: Libellulidae)
}

Paul V. Switzer

Eastern Illinois University, pvswitzer@eiu.edu

Follow this and additional works at: http://thekeep.eiu.edu/bio_fac

Part of the Behavior and Ethology Commons, Entomology Commons, and the Other Ecology and Evolutionary Biology Commons

\section{Recommended Citation}

Switzer, Paul V., "Individual variation in the duration of territory occupation by males of the dragonfly Perithemis tenera (Odonata: Libellulidae)" (2002). Faculty Research \& Creative Activity. 249.

http://thekeep.eiu.edu/bio_fac/249 


\title{
Individual Variation in the Duration of Territory Occupation by Males of the Dragonfly Perithemis tenera (Odonata: Libellulidae)
}

\author{
PAUL V. SWITZER ${ }^{1}$
}

\author{
Department of Biological Sciences, Eastern Illinois University, Charleston, IL 61920
}

\begin{abstract}
Ann. Entomol. Soc. Am. 95(5): 628-636 (2002)
ABSTRACT In the dragonfly Perithemis tenera Say, males defend territories around oviposition sites and defense of a site is critical for reproductive success. This study first demonstrated that individual males varied consistently in how long they defended a particular territory within a day (their "tenure") and in the quality of the sites they defended. I then investigated a number of factors that may have affected territory tenure and may have led to the observed variation among males. Territory occupations that ended "voluntarily" were significantly longer than those that ended because the male was evicted from his territory. For voluntary desertions, tenure duration was unrelated to age, wing length, the amount of time the male fought that day, or site quality. However, tenure durations were longer for males that arrived earlier in the day than for those that arrived later, and consistent differences existed among males in arrival time. Furthermore, tenure durations were longer when males had successfully mated than when they did not mate; available evidence suggests that this pattern may be because mating success causes them to stay longer. Thus, the results suggest that the problem of explaining tenure duration in $P$. tenera can be largely broken down into identifying factors that affect a male's likelihood of being evicted and his relative arrival time. Overall, males that defended better sites and males that had longer wings were territorial for fewer total days. Of these two factors, site quality seems to have a larger effect than wing length on the number of days, suggesting that males may incur an increased cost by defending sites that are more attractive to other males.
\end{abstract}

KEY WORDS Perithemis tenera, dragonfly, territoriality, tenure, territory quality, mating success

FOR MATING TERRITORIES, the reproductive success of the resident may be affected by factors such as the size and quality of its territory, how long it is territorial within a day (i.e., its within-day tenure), and how many days or years it is territorial (i.e., its competitive longevity) (e.g., Tsubaki and Ono 1986; Koenig 1990, Arnould and Duck 1997). These factors may interact with one another. For instance, if individuals can change territories and variation exists in the quality of available territories, individuals may be expected to spend longer on relatively high quality areas than on lower quality areas (Ueda 1994). However, if these high quality sites are limited, competition for the better sites may occur (Pezalla 1979, Tsubaki and Ono 1986, Alcock 1987, Alcock and O’Neill 1987). This competition could lead to an inverse relationship between site quality and tenure, if fighting results in lowered energetic reserves or evictions (Campanella and Wolf 1974; Alcock 1993, 2000). Alternatively, if only individuals who are the better fighters occupy the better territories (Maynard Smith 1982), territory tenure may be positively related to site quality, because those residents of high quality territories are more likely to win fights (Alcock 1993). In this latter case,

${ }^{1}$ E-mail: cfpvs@eiu.edu. we may see some measure of fighting ability (e.g., body size) correlated with tenure (Alcock 2000). Thus, the effect of site quality on territory tenure is far from straight forward. Surprisingly, however, although many studies have investigated the relationship between site quality and competition (e.g., Pezalla 1979, Severinghaus et al. 1981, Tsubaki and Ono 1986, Alcock 1987, Alcock and O’Neill 1987), relatively few studies have examined in detail how site quality or other factors affect within-day territory tenure (but see Alcock 1989a, Koenig 1990, Uéda 1994, Dunham 1998, Wolf et al. 1997).

Dragonflies (order Odonata) provide an excellent opportunity for studies on territory tenure. Many species are territorial, and their breeding behavior is well studied (reviewed in Fitzpatrick and Wellington 1983, Parr 1983, Thornhill and Alcock 1983, Corbet 1999). Individuals of many species can be readily marked and observed, and they conduct much of their breeding behavior in relatively conspicuous sites (e.g., pond edges). In addition, considerable variation exists among dragonfly species in the duration of territory tenure (reviewed in Alcock 1989a). Furthermore, studies on dragonflies represent a large proportion of the relatively small number of studies specifically looking at factors that might affect territorial tenure 
(e.g., Alcock 1989a, Koenig 1990, Uéda 1994, Dunham 1998, Wolf et al. 1997), which facilitates comparisons by focusing on a single taxonomic group.

For most dragonflies, changes in resource (e.g., oviposition site) quality during a male's territory tenure either may be negligible or may be difficult to quantify. Thus, traditional approaches used for determining patch residence time by foraging animals (which generally assume a decreasing marginal return with residence time), although successfully used in some studies of reproductive behavior (e.g., Parker 1978), do not readily apply (Krebs et al. 1974, Charnov 1976, Uéda 1994, Wolf et al. 1997). An alternative approach is to assume that the site quality is not affected appreciably by tenure length and examine how characteristics of the territory resident, the quality of the habitat, competition for territories, and specific experiences (e.g., matings, predation attempts) affect that tenure (e.g., Koenig 1990, Wolf et al. 1997).

In this study, I investigated the factors affecting territory tenure in the amberwing dragonfly Perithemis tenera Say. Male P. tenera occupy slow-moving or still water over much of eastern North America (Needham and Westfall 1954; Dunkle 1989). Males arrive at the breeding site in the morning and leave the site in the evening, and females arrive periodically throughout the day (Jacobs 1955, Switzer 1995). Males defend small territories around discrete oviposition sites, such as sticks or clumps of algae (Jacobs 1955, Switzer 1997a, 1997b). A male's reproductive lifespan is $\approx 1 \mathrm{wk}$ (Switzer 1997a). When defending a site, residents approach intruding males, and these pursuits occasionally lead to prolonged interactions between the males (Jacobs 1955, Switzer and Eason 2000, Schultz and Switzer 2001). Females arrive briefly at the water to mate and oviposit; when a male detects a female, he flies out to her and brings her back to his oviposition site. After copulation, a male hover guards the female from other males, while she oviposits (Jacobs 1955, Switzer and Schultz 2000). Males prefer to defend higher quality locations (defined by average mating rate); individuals are more likely to return to high quality sites the following day, and better sites are occupied more frequently and fought for more intensely (Switzer 1995, 1997a). The age, but not size, of the individual is correlated with the outcome of a contest: older males tend to lose to younger males (Switzer 1995). Finally, a male is more likely to return to a previously occupied site the next day (i.e., be site-faithful) if he was successful at obtaining matings at the site the day before (Switzer 1997a, 1997b). Thus, site quality, as well as some characteristics intrinsic to a male, are related to competitive ability and site choice between days.

Previous studies on the territorial behavior of $P$. tenera have focused on male territory fidelity (Switzer 1997a, 1997b), cues related to intruder detection and species recognition (Jacobs 1955, Switzer and Eason 2000, Schultz and Switzer 2001), patterns of pond occupation and competition for territories (Jacobs 1955, Switzer 2002), and factors related to the outcome of male-male interactions (P.V.S., unpublished data). In this study, my specific goals were to investigate factors (i.e., site quality, evictions, body size, age, arrival time and mating success) potentially affecting a male's within-day territory tenure and his competitive longevity (i.e., the number of days he was territorial).

\section{Materials and Methods}

This study was conducted on a small pond $(\approx 0.25$ ha) in east-central Kansas, U.S.A., in June and July 1992. The perimeter of the pond was marked every meter with surveyor's flags to facilitate recording locations. Individual males were captured and marked on their right forewing with a permanent marker and could thus be identified without recapture by using binoculars. The right forewing was also measured with calipers (to the nearest $0.01 \mathrm{~mm}$ ) for some males as an indicator of overall body size. Males territorial at the study pond were not territorial at other ponds in the area (Switzer 1995); thus, I could accurately follow a male's territorial history by focusing on just one pond. Because males were being marked daily throughout the study period, I was able to use the number of days since marking as a measure of relative, but not absolute, age (see also Switzer 1997a, 1997b).

To gather data on male locations and behaviors, I conducted instantaneous scan samples (at $\approx 2$-min intervals) for the entire time that males were present on the pond each day. For each sample, I recorded any newly present individuals, changes in the location of previous residents, fights, and matings. The scan interval was shorter than most mating sequences (unpublished data) and male-male territorial contests (P.V.S., unpublished data); although more brief matings and fights may have occasionally been missed, these omissions would not have been biased toward any particular location of the pond or any particular male (and therefore would not affect relative mating rates, see below). From these data, I could calculate the duration that an individual defended a particular oviposition site, the duration and outcome of the fights, whether an individual mated, the number of matings that occurred in particular areas, and the maximum number of males present on the pond during the day. During the study period, the maximum number of territorial males present at one time for a day averaged 14 .

Because territory boundaries were not distinct and were not necessarily consistent either within or between days, I divided the perimeter of the pond into three $\mathrm{m}$ sections for my analyses of territory quality; $3 \mathrm{~m}$ represents the approximate territory size for a male P. tenera (Jacobs 1955, Switzer 1997a). I defined site quality as the number of matings that occurred per minute that a particular section of pond was occupied over the entire study (Switzer 1997a). The sections were ranked from highest to lowest based on mating rate, and a male's section was defined by the location of his oviposition site (Switzer 1997a). Many potential oviposition sites may exist within a male's territory, but males only bring females to a single site. That is, the 
other sites within the territory are defended from other males only as a consequence of defending space around their one oviposition site. Other aspects of male $P$. tenera habitat selection and territorial behavior (e.g., site fidelity, frequency and order of territory occupation, competition for sites) are related to mating rate in a way that is consistent with this measure (i.e., mating rate) being correlated with the quality of the territory (Switzer 1997a, 2002).

Analyses required some operational definitions of particular behaviors. Territory tenure was the length of continuous time an individual spent at a particular territory divided by the total time $\geq 1$ male was present on the pond that day. This calculation yielded a proportion of the total day that the male occupied that territory and thus controlled for potential tenure differences among days (e.g., due to weather; Jacobs 1955, Switzer 2002). Second, I categorized the cause of the territory desertion as due to an eviction (i.e., territory departure immediately following an interaction with another male) or due to a voluntary desertion (i.e., territory departure without an eviction being observed and no new male immediately present on the territory after the individual departed) (Switzer 1997a). Because almost all evictions followed escalated contests and because these escalated contests lasted $>20$ min on average (P.V.S., unpublished data), it is unlikely that the cause of territory desertions was categorized incorrectly. Third, I calculated the total amount of time a male spent fighting other males (i.e., relatively extended interactions with intruders, rather than chases after passing males or brief neighborneighbor interactions) as a possible correlate of energy reserves. All else being equal, the amount of time spent fighting may correspond to the amount of energy a male has left (Marden and Waage 1990, Plaistow and Siva-Jothy 1996, Dunham 1998). However, because males may start their tenures with different energy levels, conservative conclusions will focus on the amount of time spent interacting rather than energy (Koenig 1990). Because determinates of fight outcome will be presented elsewhere and because evictions are obviously related to fighting, the analyses of fight time used only voluntary desertions. Note that residents may have fought during their tenure without a fight being the cause of their desertion.

Some analyses examine the effect of arrival time. Because arrival time tends to be affected by temperature (Switzer 2002), my measure of arrival time was relative to when the pond was first occupied by a male. Specifically, I determined the length of time the pond was occupied on a given day (i.e., the time the first male arrived to the time when the last male left), determined the latency between the first male's arrival and the arrival of the male of interest, and then divided the latency by the total time the pond was occupied. For example, if the pond was occupied by $P$. tenera males for $4 \mathrm{~h}$ on a particular day, and the male of interest arrived $1 \mathrm{~h}$ after the first male arrived, this male's time of arrival would be 0.25 for that day.

Perithemis tenera reproductive behavior is affected by weather conditions (Jacobs 1955; Switzer in press).
Accordingly, I recorded the ambient temperature once every hour during the time that $P$. tenera occupied the pond. I then examined whether the maximum temperature recorded within a day affected a male's tenure and arrival.

The overall data set included multiple samples for many males (e.g., multiple territories within a day and multiple days); I took this into account in several ways during analyses. When investigating individual variation among males in tenure, site quality, and arrival time, I included only those males that had data from at least four different days, to maintain sufficient sample size for each male for analysis by Kruskal-Wallis nonparametric analysis of variance (ANOVA). Some analyses tested for correlations within males. Because the number of observations (e.g., days) for a male tended to be small (and thus statistical significance difficult to achieve), I conducted a meta-analysis on individual correlations that examined overall patterns among the males (i.e., how many of the correlations for individual males were positive versus negative) regardless of their individual, statistical significance (e.g., Tsubaki and Ono 1987, Switzer and Eason 2000). When possible, to avoid pooling I used only used one sample per male; the datum chosen was either the first appropriate observation for the analysis (e.g., first tenure that ended voluntarily) to standardize the choice of observations among males, or the average for a male (e.g., average section rank) if using the overall average. When examining whether age affected tenure, I used the longest tenure for a particular day.

Means \pm SE are reported and nonparametric statistics take tied values into account where appropriate. Sample sizes differ among analyses due to different numbers of males and/or observations having the appropriate characteristics for a given analysis.

\section{Results}

Individual Variation in Territory Tenure. Individual males defended one or more territories for a total time per day of $209.9 \pm 6.7 \mathrm{~min}$, or $49.1 \pm 1.4 \%$ of the time the pond was occupied on a given day $(n=264$ male-days for 54 males) and averaged $1.2 \pm 0.03$ territories defended per day. On a particular territory, a male averaged $174.7 \pm 6.0 \mathrm{~min}$ or $40.8 \pm 1.4 \%$ of the time the pond was occupied in a given day $(n=316$ occupations for all males on all days; range, 12-514 $\mathrm{min})$. Overall, $64.2 \%$ of territory tenures were ended voluntarily, and $35.8 \%$ were ended because the male was evicted ( $n=316$ occupations). Using one tenure per male, the tenures for males that were evicted were considerably shorter than tenures ended voluntarily (Fig. 1; eviction ended: $24 \pm 3 \%$ of the day, $n=15$; voluntarily ended: $52 \pm 4 \%, n=37$; Mann-Whitney, $U=72.5 ; z=4.1 ; P<0.0001)$. Because of the major difference between tenures terminated voluntarily or by an eviction, the rest of the analyses distinguish between the two categories.

Variation existed among males in the proportion of the day they occupied the pond (for all days: KruskalWallis; $H=46.4$, df $=29, P=0.021$; for only days in 


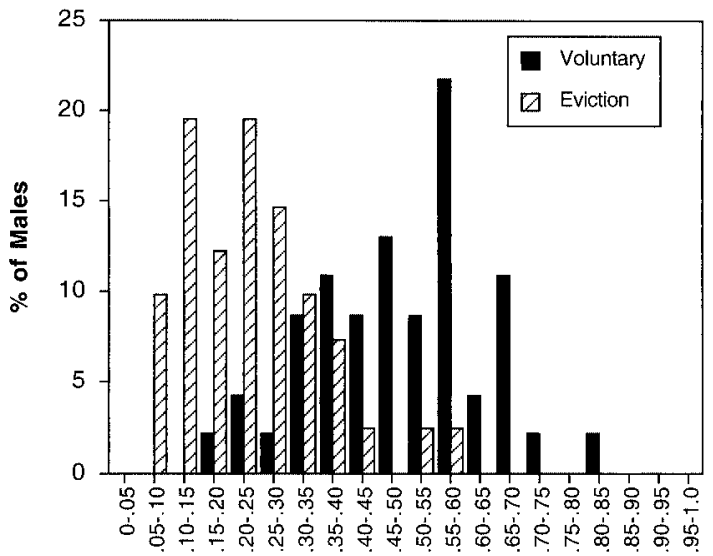

\section{Territory Tenure}

Fig. 1. Frequency distribution of the average territory tenure for individual male P. tenera. Averages consist of the first territory tenure each day that a male was territorial. Tenure is given as the proportion of the total time the pond was occupied that they defended the territory. Eviction tenures $(n=41)$ are territory occupations that ended by the resident male getting evicted. Voluntary tenures $(n=46)$ are territory occupations that ended without an eviction. This figure presents average tenures from all males that defended at least one territory; analyses of tenure variation among males given in the text use only those males that held territories on at least $4 \mathrm{~d}$.

which the male left at least one territory voluntarily: $H=31.4, \mathrm{df}=17, P=0.018)$. Variation among males also existed in their territory tenure (Fig. 1), whether both causes for departure are included $(H=47.2, \mathrm{df}=$ $31, P=0.032)$, or just voluntary departures $(H=33.1$, $\mathrm{df}=20, P=0.033$ ).

Effect of Extrinsic Characteristics on Territory Tenure. Environmental characteristics may influence territory tenure. I examined three such characteristics: temperature, territory quality and male density. Across males, temperature affected the absolute amount of time a male was present on a territory (voluntary departures; $n=45 ; \tau=0.22, z=2.1, P=$ 0.036 ) ; however, territory tenure (as defined in this paper as the proportion of the day occupied) was not related to temperature $(n=45 ; \tau=-0.025, z=0.24$, $P=0.81$ ).

Territory quality (i.e., mating rank of the section) was not correlated with territory tenure for either eviction departures $(n=15 ; \tau=0.204, z=1.06, P=$ $0.29)$ or voluntary departures $(n=37 ; \tau=0.138, z=$ $1.21, P=0.23$ ), when analyzed across males. Because individuals may respond differently to site quality, I also calculated correlations between the section rank and tenure within individual males and compared the frequency of positive and negative correlations. Section rank was not correlated with tenure for occupations ending because of an eviction (11/22 males had positive correlations; sign test, $P>0.50$ ) or voluntarily (16/27 positive correlations; sign test, $P>0.50$ ).

To investigate whether male density affected tenure, I compared the maximum number of males on the pond for a given day to the average tenure of all males that day. The maximum number of males was not related to the average tenure, whether both causes for departure are considered $(n=32, \tau=-0.169, z=1.36$, $P=0.17)$ or just voluntary departures $(n=31, \tau=$ $-0.05 \mathrm{z}=0.40, P=0.69)$. However, days on which no evictions occurred did have significantly fewer males on the pond than days in which at least one eviction did occur (no evictions: $9.8 \pm 1.4$ males, $n=5$; at least one eviction: $20.6 \pm 1.1$ males, $n=27$; Mann-Whitney; $U=132, z=3.36, P=0.0008$ )

Effect of Intrinsic Characteristics on Territory Tenure. To investigate potential body size relationships, I compared the length of a male's wing (18.2 \pm 0.093 $\mathrm{mm}$ for this $n=27$ sample) to his tenure. Male wing length was not related significantly to the average amount of total time he was territorial on the pond within a day $(n=27, \tau=0.18, z=1.74, P=0.082)$ or his average tenure on a particular territory (all tenures: $n=27, \tau=0.12, z=0.86, P=0.39$; voluntarily departures only $n=27, \tau=0.057, z=0.40, P=0.69$ ).

With respect to age, males averaged a maximum of $6.4 \pm 0.6 \mathrm{~d}$ after marking $(n=53$; range, $1-21 \mathrm{~d})$. When data from all males were pooled, territory tenure was not correlated significantly with age for tenures terminated either voluntarily $(n=203 ; \tau=0.01, z=0.21$, $P=0.83)$ or by an eviction $(n=113 ; \tau=0 .-0.069, z=$ $1.1, P=0.28$ ). Because individuals may differ in how tenure is affected by age, I examined the correlation between age and territory tenure for each male and scored the proportion of these correlations that were either positive or negative. No significant pattern was present within males for either voluntary departures (10/26 males had positive correlations between age and tenure; sign test $P>0.20$ ) or eviction departures (9/20 positive correlations; sign test $P>0.50)$. Likewise, the total amount of time a male defended any territory on the pond did not vary with age, either when all males were pooled (all days: $n=262 ; \tau=$ $0.001, z=0.027, P=0.98$; only days in which the male departed at least one territory voluntarily: $n=164 ; \tau=$ $0.025, z=0.48, P=0.63)$ or males were analyzed individually (17/45 males had positive correlations between total time and age; sign test, $P>0.20$ ). Therefore, although males differed in the total time they occupied the pond and the time they spent at a particular territory, these values did not consistently change as they aged.

I also investigated whether the amount of time a male spent fighting that day affected his tenure. Males averaged $10.3 \pm 2.8 \mathrm{~min}(n=45)$ of fighting during their tenure before leaving a territory voluntarily (range, 0-70 $\mathrm{min}$ ). Using these voluntarily-terminated tenures, I found no correlation between the amount of time a male spent fighting before leaving his territory and his tenure $(n=45 ; \tau=-0.058, z=0.70, P=0.49)$.

Furthermore, I examined whether a male's time of arrival was related to his tenure. Consistent differences existed among males in when they began defending territories on the pond $(H=60.6, \mathrm{df}=29, P=$ 0.0003 ). For tenures that ended voluntarily, males that arrived earlier tended to have longer tenures (Fig. 2; 


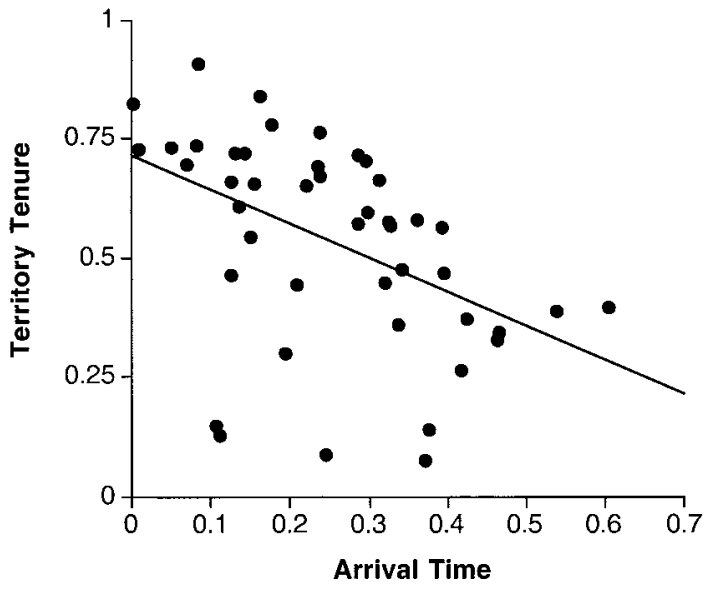

Fig. 2. Tenure for a male P. tenera as related to the time he arrived that day. Time of arrival was determined by calculating when the male began his defense of the territory relative to the total time the pond was occupied that day (see Materials and Methods for details). Tenure is given as the proportion of the total time the pond was occupied that they defended the territory. The first voluntary tenure was used for each male. The line represents a simple linear fit to the data.

$n=45$; Kendall's $\tau, \tau=-0.41, z=3.93, P<0.0001$ ); no significant pattern existed for tenures that ended by eviction $(n=15 ; \tau=0.048, z=0.25, P=0.80)$. For those males that had both voluntary departures and eviction departures (i.e., for their first tenures on different days), average arrival time tended to be relatively earlier in the day for those days in which they were evicted from their first territory $(n=27$; eviction arrival $=0.18 \pm 0.020$; voluntary arrival $=$ $0.24 \pm 0.022$; Wilcoxon signed rank test, $T=85, P=$ 0.02 ). A male's average arrival time was not significantly correlated with his wing length $(n=33 ; \tau=$ $-0.036, z=0.30, P=0.77$ ), nor did a male consistently change his arrival time as he became older (22/44 males had positive correlations between age and arrival time; sign test, $P>0.5)$. In general, most males tended to arrive well before most females arrived (Fig. $3)$. Relative arrival time was not affected by temperature (voluntary departures; $n=45 ; \tau=-0.05, z=$ $0.47, P=0.64)$.

Finally, I examined whether a male's mating experience (i.e., whether he had successfully mated on the territory that day) affected his tenure. I performed a within-male analysis on those males who had both tenures with a mating and tenures without a mating (using all territory tenures for all days). Including only voluntary desertions, an individual's tenure was relatively longer if he had a mating versus if he did not (mean difference $=0.15 \pm 0.032 ; n=24$; Wilcoxon signed rank test; $T=23 ; P=0.0003$ ). This difference remained significant if only those days were included during which the individual occupied a single territory (i.e., one tenure represented the entire territorial occupation period for that male) (mean difference $=$

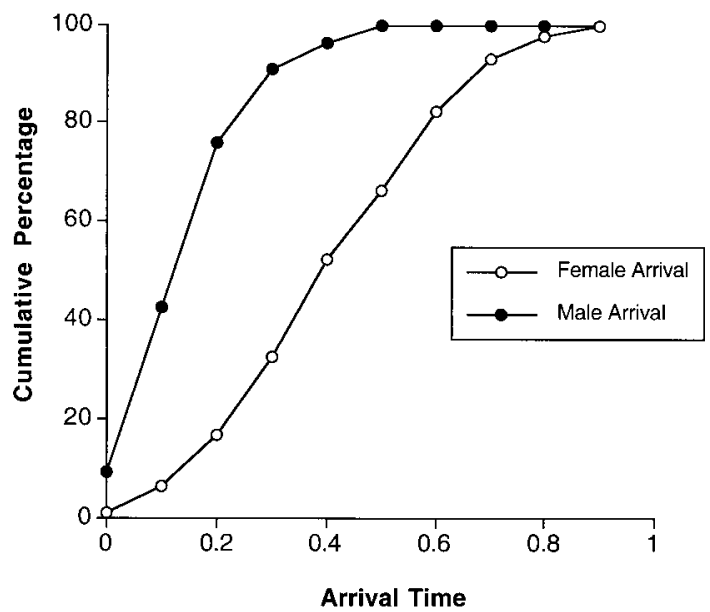

Fig. 3. Cumulative arrival of male $(n=54)$ and female ( $n=273$ matings) P. tenera. Time of arrival was determined by calculating when the male began his defense of the territory or when a female mated, relative to the total time the pond was occupied that day. Data for males represent the average arrival time for each male.

$0.095 \pm 0.035 ; n=23 ; T=52.5 ; P=0.009)$. Therefore, either males stayed longer because they had a mating or they had a mating because they stayed longer. To try to tease these two possibilities apart, I calculated when during his tenure a male first mated. For the 28 males that mated (and voluntarily deserted their only territory of the day), the mating occurred and average of $36.5 \pm 4.2 \%$ through their tenure. Therefore, the mating occurred relatively early in the tenure, which suggests that males were not simply mating because they stayed longer. In addition, although males that arrived earlier tended to have longer tenures (see above), tenures resulting in a mating did not tend to occur from earlier arrivals, on average, than those that did not result in a mating (mean arrival time difference, mating -nonmating $=-0.001 ; n=24 ; T=147.5$, $P=0.94)$.

Characteristics Related to Male Competitive Longevity. The number of days a male was territorial (i.e., his competitive lifespan) was examined with respect to average total time per day he was territorial, his average territory tenure, his average site quality, and his wing length. Males were territorial for an average of $5.3 \pm 0.64 \mathrm{~d}(n=44)$. Competitive lifespan was not significantly correlated with the average total time per day he was territorial $(n=44, \tau=0.18, z=1.74, P=$ 0.082 ) or his average territorial tenure over his lifetime (all tenures: $n=44, \tau=0.12, z=1.10, P=0.27$; voluntary departures only: $n=41, \tau=0.17, z=1.59$, $P=0.11)$.

Males consistently differed in the quality of the territories they tended to defend during their lifespan $(H=59.3, \mathrm{df}=30, P=0.001)$. Although highly variable, the average quality of a male's territory was negatively correlated with the number of days he was territorial (Fig. 4; $n=42, \tau=-0.22, z=2.08, P=$ 


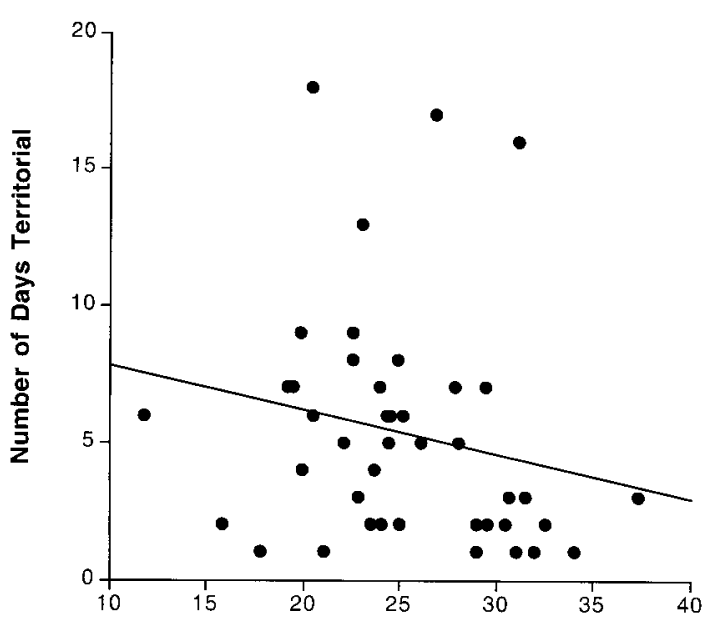

Average Rank

Fig. 4. Number of days a male P. tenera was territorial as related to the average rank of the section he occupied $(n=$ 42); higher ranking sections had higher mating rates over the season. The line represents a simple linear fit to the data.

0.037 ), indicating that males who, on average, defended better territories tended to defend territories on fewer days. Furthermore, there was a borderline trend for males with longer wings to defend territories for fewer days $(n=27, \tau=-0.26, z=1.93, P=0.053)$. Wing length and average site quality, however, were not correlated, $(n=27, \tau=-0.084, z=0.59, P=0.56)$, and a multiple regression analysis that included both wing length and average site quality suggested that site quality explains more variation in the number of days a male defended a territory (Adjusted $R^{2}=0.13 ; F=$ $2.8 ; \mathrm{df}=2,24 ; P=0.08 ; \beta_{\text {site quality }}=-0.41, t=2.15$, $\left.P=0.043 ; \beta_{\text {wing length }}=-2.69, t=1.34, P=0.19\right)$.

One possible explanation for the reduced longevity of males defending better sites is that these males had to fight more. To investigate this possibility, I compared the average quality of a male's territory with the average amount of time he spent fighting per territorial day; the correlation between these two variables was not significant $(n=44, \tau=-0.064, z=0.60, P=$ $0.55)$. Thus, on average, males that occupied better territories did not fight proportionately more than males that defended poorer territories.

\section{Discussion}

On average, a male $P$. tenera defended a single territory per day for approximately half of the time the pond was occupied. Interestingly, individual males varied in the amount of time they spent at a particular territory and the amount of time they spent on the pond within a day. Other studies on odonates have also found consistent, individual variation in tenure (e.g., Koenig 1990, Wolf et al. 1997). Below, I will first discuss the evidence for causes of differences in territory tenure in $P$. tenera, relate these results to other studies of tenure in odonates, and then examine the possible explanations for the observed differences in the number of days a male was territorial.

Factors Affecting Tenure. Not surprisingly, evictions resulted in shorter tenures on average. This result is consistent with Alcock's (Alcock 1989a) observations that males of the dragonfly Brechmorhoga pertinax (Hagen) often left after brief interactions with other males and the observation that evictions play an important role in territory turnover for many insects (Alcock 1993). Evictions were also responsible for terminating tenure in other odonates, such as Plathemis lydia Drury (Campanella and Wolf 1974), Nannophya pygmaea Rambur (Tsubaki and Ono 1986), and Paltothemis lineatipes Karsch (Alcock 1987b, 1989b). The result, however, contrasts with Wolf et al.'s (1997) finding that evictions were a not major factor influencing the territory tenure of the dragonfly Leucorrhinia intacta Hagen. One possible explanation for the difference in the effect of evictions for $L$. intact $a$ and $P$. tenera is that L. intact a frequently change sites within a day (Wolf et al. 1997), while P. tenera typically only defended one territory each day (see also Jacobs 1955). The probable consequence of frequent site shifts is that sites will frequently become open, lowering the value to fighting for any particular location. In contrast, in $P$. tenera, if the site is occupied then it is likely to be occupied for most of the day, making it less likely that it will be available without a fight. Superficially, the behavior of B. pertinax appears not to support this "site limitation hypothesis" for the importance of evictions. Male B. pertinax only briefly occupy a location before leaving a site $(\approx 30 \mathrm{~min})$, even if not evicted (Alcock 1989a). The interactions that lead to their leaving, though, are relatively short, with the maximum duration of $\approx 2 \mathrm{~min}$. Thus, like $L$. intacta but unlike $P$. tenera, $B$. pertinax change sites frequently and do not have extended contests for territories. This suggests that site limitation is not a major factor governing the behavior of either L. intacta or B. pertinax.

Therefore, part of solving the puzzle of tenure duration is determining why males get evicted. For $P$. tenera, residents tend to lose territory contests when they are older than the intruder and when they have fought relatively more than the intruder (P.V.S., unpublished data). Therefore, a male's territory tenure is partially determined by who attempts to takeover his territory. However, although evictions affected tenure in $P$. tenera, there was little evidence that the amount of competition for territories on the pond (i.e., the number of males) affected the likelihood of eviction. Density was also found to be unrelated to tenure in the odonates Cercion c. calamorum Ris (Uéda 1994) and L. intacta (Wolf et al. 1997) but did affect tenure in Pachydiplax longipennis Burmeister (Dunham 1998).

Even with voluntarily ended tenures, other studies on territorial odonates have found that the number or intensity of interactions with other males is negatively correlated with tenure, likely as a result of energy depletion (e.g., Koenig 1990, Dunham 1998). Site quality also has been shown to be negatively correlated 
with tenure perhaps because of increased interactions with other males (Koenig 1990; but see Uéda 1994, Wolf et al. 1997). In an experimental study, Dunham (1998) manipulated energy levels in P. longipennis by supplemental feeding and found that males that were supplementally fed had higher fat levels and longer tenures. In $P$. tenera, neither the amount of time spent fighting that day (a possible correlate for energy levels; Koenig 1990, Dunham 1998) nor site quality was related to tenure for occupations ended voluntarily, even though more fighting occurs on higher quality sites (Switzer 2002) and males that have fought more in a particular day are more likely to lose escalated interactions (P.V.S., unpublished data). Without assessing actual fat levels (e.g., Marden and Waage 1990, Plaistow and Siva-Jothy 1996, Dunham 1998); however, one cannot conclusively discount the role of energy limitation in determining tenure duration.

I found no evidence that measurable characteristics of individual males, in particular size and age, affected their tenure on a territory or the total time they spent on the pond. Size was not related to daily tenure in the dragonfly Orthetrum japonicum (Kasuya et al. 1997) but was related in P. lydia (Koenig and Albano 1985). For $P$. tenera, the lack of a size effect is not surprising; they have noncontact fights (Jacobs 1955, Switzer 1995, Switzer and Schultz 2000), and body size is not correlated with an individual's ability to win these fights (P.V.S., unpublished data). Age, however, is related to competitive ability and site fidelity, with older males being less likely to win fights but more likely to return to the same territory the next day (Switzer 1997a; P.V.S., unpublished data). In addition, in other territorial odonates, older individuals have lower energy reserves (Marden and Waage 1990, Marden and Rollins 1994, Plaistow and Siva-Jothy 1996). Thus, it is interesting that age is not correlated with tenure, and the explanation for this result is not immediately apparent. One possibility that an interaction exists between age and site quality (e.g., that older individuals tend to defend poor quality sites resulting in the age effect disappearing) can be rejected; older individuals that can still defend a territory do not defend sites of decreasing quality as they age (Switzer 1997a). No other odonate studies have investigated whether size or age affects within-day tenure, so the generality of the results from $P$. tenera for these characteristics is unknown.

Other than evictions, the clearest factor affecting a male's tenure was his relative time of arrival at the pond; later arriving males had shorter tenures. Therefore, for voluntary departures, the answer for why a male had a tenure of a certain length might be the same answer as for why he arrived on the pond at a certain time. In other odonates, relative arrival time has been suggested to related tradeoffs between energy levels, competition for territories, and the opportunity for mating (e.g., Koenig and Albano 1985, Poethke and Kaiser 1985, Alcock 1987). For P. tenera, male and female arrival is generally correlated, with females tending to begin arriving $\approx 1 \mathrm{~h}$ after males arrive and stop arriving $\approx 1 \mathrm{~h}$ before males leave the pond (P.V.S., unpublished data). Almost all males, however, arrived at the pond well before most females arrived, and female arrival was generally consistent for a relatively long period of time (Fig. 3 ). Therefore, it is not as if the differences among males in arrival time and tenure reflected some males arriving before, some during, and some after the peak time of female arrival. Thus, if female arrival pattern was responsible for the consistent differences in arrival among males, males must have "fine-tuned" how much earlier they arrived than females based on characteristics, such as their physiological condition, competitive abilities, and prior residency status.

Temperature also affects arrival time in P. tenera; breeding sites are occupied earlier and for longer on relatively warmer days (Switzer 2002). Furthermore, this study showed that temperature affected the absolute amount of time a male stayed on a territory, presumably by affecting the total amount of time the temperature was sufficient for occupying the pond (Switzer 2002). But, because I used relative, rather than absolute, arrival time and tenure, I can rule out the possibility that either the arrival time -tenure or the temperature -tenure relationship was caused by temperature or other weather factors. Indeed, no correlation existed between relative arrival time or relative tenure and the maximum temperature that day. However, differences in energy levels or thermoregulatory abilities among males may lead to variation in arrival times. In this study, two potential correlates of energetic or thermoregulatory differences, age and body size, were not significantly related to arrival time for $P$. tenera. Finally, because adult male $P$. tenera rarely forage on the pond, their energy gain would be primarily limited to the periods before and/or after their territory tenure. Consequently, it would be interesting to examine whether different arrival times reflect (or lead to) variation in foraging behavior.

Lastly, a male's mating success may have also affected his tenure. On average, a male stayed longer on territories when he had a mating than when he did not have a mating. Whether mating success was a cause or a consequence of longer tenures remains unclear, but because matings tended to occur relatively early in the male's tenure, it seems unlikely that mating success was simply a consequence of longer tenures. Wolf et al. (1997) found that L. intacta tenures were also positively related to mating success but concluded that this was likely due to males with longer tenures being more likely to mate. Dunham (1998) found no effect of female presence on tenure, and Koenig (1990) found a negative correlation between tenure and mating rate. Koenig (1990) suggested that the negative correlation might have been caused by the negative relationship between site quality and tenure in P. lydia (discussed above). To properly determine the causality between mating success and tenure, one would need to manipulate mating success experimentally and examine the resulting tenure. Switzer (1997b), manipulated mating success in P. tenera for a different purpose: to examine the effect of mating success on the likelihood of returning to the same 
territory the next day. In that study, males that did not mate had shorter tenures, on average, than males that did mate, but the tenures were highly variable, and the difference was not statistically significant. However, I cannot rule out the possibility that the mating successtenure correlation found in this study is an artifact of the methods used to collect data. It is possible that on rare occasions, some matings were missed for some males. Given that a male was successfully mating, the longer his tenure, the less likely it would have been that I would have missed all of his matings and have recorded him as "not mating." Consequently, missed matings for short-tenured males may have resulted in a spurious, positive correlation between mating success and tenure.

Overall, the strongest factors related to the tenure of a male $P$. tenera were evictions and arrival time. The role of external disturbances, such as predation events or genetic predispositions to certain tenure durations (Wolf et al. 1997), could not be tested with my data. However, I did observe one male shift locations after a failed predation attempt by a fish, and very early in their tenure (e.g., during the settlement process) males seem particularly sensitive to disturbance from predators or humans (Jacobs 1955). But once established on a territory, male $P$. tenera will return to the same location even after repeatedly being disturbed by (unsuccessful) capture attempts with a net. Furthermore, most of the time I did observe a male leaving his territory, it was either due to a male getting evicted or a male simply flying away from his territory and off the pond for the day. Therefore, it seems unlikely that external disturbances account for a large proportion of tenure departures.

Factors Affecting Competitive Lifespan. Although body size and site quality were unrelated to a male's tenure within a day, both of these factors were negatively correlated with the number of days a male defended a territory on the pond. In contrast, size was positively correlated with competitive lifespan in the dragonfly Nannophya pygmaea Rambur (Tsubaki and Ono 1987). In P. tenera, the inverse relationship between site quality and competitive lifespan appeared to be stronger than that between size and competitive lifespan. At least two possible explanations exist for the negative correlation between site quality and competitive lifespan. First, a competitive trade-off may exist, with males that occupy higher quality territories having to fight more and thus, although perhaps achieving higher mating success, having shorter lifespans (Alcock 1993, 2000). In P. tenera, however, the average territory quality for a male was not significantly correlated with the average amount of time they spent fighting, even though, in general, more fighting occurs at higher quality sites and higher quality sites were more likely to have escalated fights (Switzer 2002). But, as for within-day tenure (see above), I am unable to rule out possible energy limitation without information on fat content and rates of change of fat content of males on territories of varying quality. Second, the relationship between site quality and competitive lifespan may have been a conse- quence of males being less competitive as they age (e.g., Forsyth and Montgomerie 1987, Tsubaki and Ono 1987) and therefore only able to defend lower quality territories when they were older. Consequently, the average quality of a male's territory would decrease the longer he was alive and territorial on the pond. In $P$. tenera, male competitive ability is negatively related to age (P.V.S., unpublished data), but males do not tend to defend lower quality territories when they are older (Switzer 1997a). Thus, although the correlation between site quality and competitive lifespan may accurately reflect a tradeoff between territory quality and competition, the actual cause of this pattern remains elusive.

\section{Acknowledgments}

I thank A. B. Switzer, C. Schif, and D. Schif for access to and assistance at the study site. J. Stamps, M. Mangel, I. Switzer, and J. Switzer provided useful guidance throughout the study. S. Chambers and L. Switzer assisted with some of the data analyses, and T. Shelly, L. Switzer, and two anonymous reviewers gave helpful comments on early versions of the manuscript. This work was partially supported by a Council of Faculty Research grant from Eastern Illinois University.

\section{References Cited}

Alcock, J., and K. M. O'Neill. 1987. Territory preferences and intensity of competition in the grey hairstreak Strymon melinus (Lepidoptera: Lycaenidae) and the tarantula hawk wasp Hemipepsis ustulata (Hymenoptera: Pompilidae). American Midland Naturalist 11: 120-138.

Alcock, J. 1987a. The effects of experimental manipulation of resources on the behavior of two calopterygid damselflies that exhibit resource-defense polygyny. Can. J. Zool. 65: 2475-2482.

Alcock, J. 1987b. Male reproductive tactics in the libellulid dragonfly Paltothemis lineatipes: temporal partitioning of territories. Behaviour 103: 157-173.

Alcock, J. 1989a. The mating system of Brechmorhoga pertinax (Hagen): the evolution of brief patrolling bouts in a "territorial" dragonfly (Odonata: Libellulidae). J. Insect Behav. 2: 49-62.

Alcock, J. 1989b. Annual variation in the mating system of the dragonfly Paltothemis lineatipes (Anisoptera: Libellulidae). J. Zool. 218: 597-602.

Alcock, J. 1993. Differences in site fidelity among territorial males of the carpenter bee Xylocopa varipuncta (Hymenoptera: Anthophoridae). Behaviour 125: 199-217.

Alcock, J. 2000. Possible causes of variation in territory tenure in a lekking pompilid wasp (Hemipepsis ustulata) (Hymenoptera). J. Insect Behav. 13: 439-453.

Arnould, J.P.Y., and C. D. Duck. 1997. The cost and benefits of territorial tenure, and factors affecting mating success in male Antarctic fur seals. J. Zool. 241: 649-664.

Campanella, P. J., and L. L. Wolf. 1974. Temporal leks as a mating system in a temperate zone dragonfly (Odonata: Anisoptera) I: Plathemis lydia (Drury). Behaviour 51: $49-87$.

Charnov, E. L. 1976. Optimal foraging: the marginal value theorem. Theoret. Pop. Biol. 9: 129-136.

Corbet, P. S. 1999. Dragonflies: behaviour and ecology of Odonata, Harley Books, Martins, England.

Dunham, M. L. 1998. Territory tenure in a libellulid dragonfly. Regenerative Science Institute's Biolitera- 
ture Repository (http: / / biolit.regensci.org/ repository / 19981226221522/19981226221522.html).

Dunkle, S. W. 1989. Dragonflies of the Florida peninsula, Bermuda, and the Bahamas. Scientific Publishers, Gainesville, FL.

Fitzpatrick, S. M., and W. G. Wellington. 1983. Insect territoriality. Can. J. Zool. 61: 471-486.

Forsyth, A., and R. D. Montgomerie. 1987. Alternative reproductive tactics in the territorial damselfly Calopteryx maculata: sneaking by older males. Behav. Ecol. Sociobiol. 21: 73-81.

Jacobs, M. E. 1955. Studies on territorialism and sexual selection in dragonflies. Ecology 36: 566-586.

Kasuya, E., K. Edanami, and I. Ohno. 1997. Territorial conflicts in males of the dragonfly, Orthetrum japonicum japonicum (Odonata: Libellulidae): the role of body size. Zool. Sci. 14: 505-509.

Koenig, W. D. 1990. Territory size and duration in the white-tailed skimmer Plathemis lydia (Odonata: Libellulidae). J. Anim. Ecol. 59: 317-333.

Koenig, W. D., and S. S. Albano. 1985. Patterns of territoriality and mating success in the white-tailed skimmer Plathemis lydia (Odonata: Anisoptera). Am. Midl. Nat. 114: 1-12.

Krebs, J. R., J. C. Ryan, and E. L. Charnov. 1974. Hunting by expectation or optimal foraging? A study of patch use by chickadees. Anim. Behav 22: 953-964.

Marden, J. H., and R. A. Rollins. 1994. Assessment of energy reserves by damselflies engaged in aerial contests for mating territories. Animal Behaviour 48: 1023-1030.

Marden, J. H., and J. K. Waage. 1990. Escalated damselfly territorial contests are energetic wars of attrition. Anim. Behav. 39: 954-959.

Moore, A. J. 1989. The behavioral ecology of Libellula luctuosa (Burmeister) (Odonata: Libellulidae): III. Male density, OSR, and male and female mating behavior. Ethology 80: 120-136.

Moore, A. J. 1990. The evolution of sexual dimorphism by sexual selection: the separate effects of intrasexual and intersexual selection. Evolution 44: 315-331.

Needham, J. G., and M. J. Westfall, Jr. 1954. A manual of the dragonflies of North America (Anisoptera), University of California Press, Berkeley, CA.

Parker, G. A. 1978. Searching for mates, pp. 214-244. In J. R. Krebs and N. B. Davies (eds.), Behavioural ecology: an evolutionary approach. Blackwel, Oxford.

Parr, M. J. 1983. An analysis of territoriality in libellulid dragonflies (Anisoptera: Libellulidae). Odonatologica 12: $39-57$.

Plaistow, S., and M. T. Siva-Jothy. 1996. Energetic constraints and male mate-securing tactics in the damselfly Calopteryx splendens xanthostoma (Charpentier). Proc. R. Soc. Lond. B. 263: 1233-1238.

Pezalla, V. M. 1979. Behavioral ecology of the dragonfly Libellula pulchella Drury (Odonata: Anisoptera). Am. Midl. Nat. 102: 1-22.
Poethke, H. J., and Kaiser, H. 1985. A simulation approach to evolutionary game theory: the evolution of time-sharing behavior in a dragonfly mating system. Behav. Ecol. Sociobiol. 18: 155-163.

Severinghaus, L. L., B. H. Kurtak, and G. C. Eickwort. 1981. The reproductive behavior of Anthidium manicatum (Hymenoptera: Megachilidae) and the significance of size for territorial males. Behav. Ecol. Sociobiol. 9: 51-58.

Schultz, J. K., and P. V. Switzer. 2001. Pursuit of heterospecific targets by territorial amberwing dragonflies (Perithemis tenera): a case of mistaken identity. J. Insect Behav. 14: 607-620.

Smith, J. Maynard. 1982. Evolution and the theory of games. Cambridge University Press, Cambridge.

Switzer, P. V. 1995. Influences on the site fidelity of territorial animals: theoretical and empirical studies. Ph.D. dissertation, University of California, Davis.

Switzer, P. V. 1997a. Factors influencing the site fidelity of a territorial animal, Perithemis tenera. Anim. Behav. 53 865-877.

Switzer, P. V. 1997b. Past reproductive success affects future habitat selection. Behav. Ecol. Sociobiol. 40: 307-312.

Switzer, P. V. 2002. Territory quality, habitat selection, and competition in the amberwing dragonfly, Perithemis tenera (Odonata: Libellulidae): population patterns as a consequence of individual behavior. J. Kans. Entomol. Soc.

Switzer, P. V., and P. K. Eason. 2000. Proximate constraints on intruder detection in the dragonfly Perithemis tenera (Odonata: Libellulidae): effects of angle of approach and background. Ann. Entomol. Soc. Am. 93: 333-339.

Switzer, P. V., and J. K. Schultz. 2000. The male-male tandem: a novel form of mate guarding in Perithemis tenera (Say) (Anisoptera: Libellulidae). Odonatologica 29: 157161.

Thornhill, R., and J. Alcock. 1983. The evolution of insect mating systems. Harvard University Press, Cambridge, MA.

Tsubaki, Y., and T. Ono. 1986. Competition for territorial sites and alternative mating tactics in the dragonfly, Nannophya pygmaea Rambur (Odonata: Libellulidae). Behaviour 97: 234-252

Tsubaki, Y., and T. Ono. 1987. Effects of age and body size on the male territorial system of the dragonfly, Nannophya pygmaea Rambur (Odonata: Libellulidae). Anim. Behav. 35: 518-525.

Uéda, T. 1994. Spatial distribution of mate-searching males in the damselfly, Cercion c. calamorum (Odonata: $\mathrm{Zy}$ goptera). J. Ethol. 12: 97-105.

Wolf, L. L., E. C. Waltz, D. Klockowski, and K. Wakeley. 1997. Influences on variation in territorial tenures of male white-faced dragonflies (Leucorrhinia intacta) (Odonata: Libellulidae). J. Insect Behav. 10: 31-47.

Received for publication 31 July 2001; accepted 30 April 